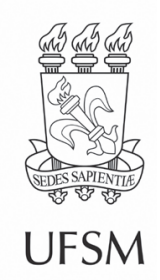

\title{
Artigos
}

\section{Alterações fisiológicas em mudas de Eucalyptus grandis (Hill) ex Maiden submetidas à fertilização nitrogenada e ação do etileno}

\section{Physiological changes in seedlings of Eucalyptus grandis (Hill) ex Maiden submitted to nitrogen fertilization and ethylene}

\author{
Deisinara Giane Schulz ${ }^{\oplus}$, Michelle Cristina Ajala 11 , \\ Marlene de Matos Malavasi " $₫$, Ubirajara Contro Malavási " $\odot$ \\ I Instituto Federal do Paraná, Assis Chateaubriand, PR, Brasil \\ " Universidade Estadual do Oeste do Paraná, Marechal Cândido Rondon, PR, Brasil
}

\section{RESUMO}

\begin{abstract}
A fertilização e a rustificação durante a produção das mudas de espécies lenhosas promovem alterações morfofisiológicas que potencializam o crescimento e minimizam os danos por estresse após o plantio a campo. O experimento objetivou avaliar a fertilização nitrogenada durante a produção e quantificar as alterações na morfogênese após a aplicação de etileno em mudas de Eucalyptus grandis (Hill) ex Maiden. O experimento foi conduzido em casa de vegetação localizada sob as coordenadas $24^{\circ} 33^{\prime} \mathrm{S}$ e $54^{\circ} 04^{\prime}$ $\mathrm{O}$, em delineamento de blocos casualizados em esquema fatorial com testemunha adicional $(3 \times 4+1)$ composto por três regimes de fertilização (100 mg L-1 de $\mathrm{N}$ convencional, $100 \mathrm{mg} \mathrm{L}^{-1}$ de $\mathrm{N}$ exponencial e zero $\mathrm{N}$ ) aplicados durante três meses (nove aplicações) e quatro aplicações aditivas de etileno de 1.000 mg L-1 mais uma testemunha sem aplicação do regulador vegetal com seis repetições de cinco mudas por parcela. As fertilizações, exponencial e convencional, bem como as aplicações semanais de etileno induziram alterações fisiológicas na fase de rustificação em mudas de Eucalyptus grandis. Os regimes de fertilização externaram efeitos semelhantes com duas aplicações de etileno, reduzindo a concentração de fósforo e potássio e estimulando o acúmulo de lignina na parede celular de raízes. Não houve efeito dos regimes de fertilização e das aplicações de etileno sobre a sobrevivência em mudas de Eucalyptus grandis.
\end{abstract}

Palavras-chave: Rustificação; Produção de mudas; Fertilização exponencial; Eucalipto 


\section{ABSTRACT}

Fertilization and hardening during seedling production are extremely important to promote morphophysiological changes that enhance growth and minimize the stress damage after field planting. This experiment aimed to evaluate nitrogen fertilization during production of Eucalyptus grandis (Hill) ex Maiden seedlings and to quantify morphometric changes. The experiment was conducted in a greenhouse located at $24^{\circ} 33$ ' $\mathrm{S}$ and $54^{\circ} 04^{\prime} \mathrm{W}$ in a randomized complete block design in a factorial scheme with an additional control $(3 \times 4+1)$ composed by three regimes of fertilization (100 $\mathrm{mg} \mathrm{L}^{-1}$ conventional $\mathrm{N}, 100 \mathrm{mg} \mathrm{L}^{-1}$ exponential $\mathrm{N}$ and zero $\mathrm{N}$ ) applied for three months (nine applications) and four ethylene applications of $1000 \mathrm{mg} \mathrm{L}^{-1}$ more one control without application of plant regulator with six replicates of five plants per plot. Fertilization, both exponential or conventional, as well as the weekly application of ethylene, induced physiological changes ofEucalyptus grandis seedlings during hardening. Fertilization regimes presented similar effects with two ethylene applications, reducing phosphorus and potassium levels and stimulating the accumulation of lignin in the cell wall of roots. There was no effect of the fertilization regimes and the ethylene application on the survival of Eucalyptus grandis seedlings.

Keywords: Hardening; Seedling production; Exponential fertilization; Eucalyptus

\section{INTRODUÇÃO}

O sucesso na produção e sobrevivência de mudas de espécies lenhosas a campo estão associados à utilização de técnicas adequadas que possibilitem bom crescimento, com menor custo para o viveirista, aliadas a práticas silviculturais sustentáveis. Estudos sugerem a existência de uma relação positiva entre a sobrevivência em viveiro e a fertilização nitrogenada, atestando que o estado nutricional é importante para explicar o desempenho pós-plantio (OLIET et al., 2009).

As espécies do gênero Eucalyptus apresentam-se como as espécies lenhosas com características de alta produtividade, crescimento rápido e de adaptação a diferentes condições ambientais, sendo que Eucalyptus grandis é a espécie florestal mais plantada no Brasil (SOUZA et al., 2006; INDÚSTRIA BRASILEIRA DE ÁRVORES, 2018). O crescimento e a sobrevivência do eucalipto nos plantios em condições adversas associam-se ao fato de a muda ser potencialmente aclimatada às adversidades de campo, principalmente no que diz respeito à umidade, aos atributos químicos do solo, ao manejo e tratos culturais, resultando que muitas não sobrevivam, implicando em replantios e em povoamentos heterogêneos (LOPES et al., 2011). Desse modo, estudos 
sobre aclimatação de mudas de eucalipto podem caracterizar-se como ferramenta importante para o desenvolvimento inicial de povoamentos florestais.

A eficiência do uso de fertilizantes pelas plantas, garantindo maior reserva de nutrientes e, por conseguinte, menor perda destes nutrientes no solo, caracterizase como prática relevante no processo de produção de mudas. Segundo Carrasco et al. (2001), o crescimento e o acúmulo de nutrientes em mudas fertilizadas de forma "clássica" ou convencional aumentam progressivamente. Porém, a concentração interna de nutrientes geralmente diminui em função do maior crescimento da muda, sugerindo um estresse devido à alta quantidade de nutrientes no início do crescimento e a uma possível carência ao final. Aquele mesmo autor sugeriu que a fertilização exponencial pode garantir o acúmulo de nutrientes no processo de produção; isto é, porque se desenha como um aumento regular de nutrientes, no qual as plantas devem crescer com uma concentração interna de nutrientes constantes e livre de estresse nutricional.

Em contrapartida, estudos evidenciaram relação negativa entre o crescimento e a fertilização exponencial, principalmente devido ao crescimento descontínuo da espécie, não coincidindo com a adubação exponencial em viveiro (VILLAR-SALVADOR et al., 2004; OLIET et al., 2009).

Após a fase de crescimento, a fase de rustificação também pode determinar o sucesso ou fracasso no estabelecimento das mudas no campo. Na rustificação, as mudas são expostas a alguma forma de estresse a fim de provocar mudanças morfofisiológicas para aumentar a sobrevivência pós-plantio. A exposição das mudas a determinadas formas de estresse pode induzir ao aumento da concentração de auxina até promover a síntese de etileno pelo aumento da atividade da ACC sintase (ERNER; JAFFE, 1982). O aumento na síntese de etileno pode induzir a atividade das peroxidases em plantas, que ocorre em resposta a vários estímulos bióticos e abióticos, incluindo a exposição a agente de oxidação química, patógenos, luz vermelha, e a estímulos mecânicos (CASAL et al., 1994). 
Donald e Cipollini (1998) destacaram que as peroxidases desempenham funções no catabolismo da auxina e na oxidação de compostos fenólicos de modo a formar a lignina. Além disso, essas enzimas fazem parte da arquitetura das glicoproteínas ricas em hidroxiprolina na parede celular das plantas, bem como a produção e composição de peróxido de hidrogênio e outras espécies reativas de oxigênio.

O etileno promove diversos efeitos fisiológicos, dentre eles o crescimento de raízes e suas ramificações. Adicionalmente, o etileno inibe a ação e a translocação das auxinas na parte aérea do vegetal, o que altera o padrão de crescimento e expansão celular, aumenta a atividade da celulase nas zonas de abscisão e eleva a síntese de lignina (YAMADA; CASTRO, 2007). Segundo Monteiro, Pereira e Abreu (2004), a lignina tem papel importante na sustentação, promovendo a rigidez na madeira, fluidez do transporte de água na planta e maior resistência contra patógenos.

Pesquisas têm demonstrado a indução da aclimatação e resistência de mudas ao plantio a campo em resposta à utilização da aplicação exógena de etileno. Essa técnica pode ser uma forma alternativa de obter a rusticidade por meio do estímulo químico, surgindo como alternativa para melhoria da qualidade das mudas para sobreviverem após o plantio a campo (ORO et al., 2012; DRANSKI et al., 2013).

No entanto, são poucas as informações sobre a utilização de reguladores de crescimento vegetal na fase de rustificação em mudas de espécies lenhosas de interesse florestal. Assim, este experimento objetivou quantificar alterações morfofisiológicas em mudas de eucalipto submetidas a regimes de fertilização nitrogenada e aplicação de etileno ao final do ciclo de produção.

\section{MATERIAL E MÉTODOS}

O experimento foi conduzido em ambiente protegido não-climatizado no município de Marechal Cândido Rondon-PR com coordenadas de $24^{\circ} 33^{\prime} \mathrm{S}$ e $54^{\circ} 04^{\prime} \mathrm{O}$ a uma altitude de 420 m durante 2012 e 2013.

O clima local é caracterizado como subtropical úmido, recebendo a classificação 
de Cfa, segundo Köppen, com verões quentes, geadas pouco frequentes e tendência a concentração de chuvas nos meses de verão. A estação seca não é definida, a precipitação média anual é de $1.500 \mathrm{~mm}$, a umidade média anual é de $80 \%$ e a temperatura média anual é de $21^{\circ} \mathrm{C}$, com máxima média de $28^{\circ} \mathrm{C}$ e mínima média de $15^{\circ} \mathrm{C}$. Durante o experimento, a temperatura média variou de 14 a $37^{\circ} \mathrm{C}$ e a umidade de 30 a $60 \%$, ambas aferidas com datalogger autoprogramado.

As mudas de Eucalyptus grandis foram propagadas com sementes adquiridas comercialmente, via semeadura em tubetes cônicos de $120 \mathrm{~cm}^{3}$ preenchidos com substrato comercial (Mecplant $®$ ) em abril de 2012, os quais foram acomodados em bandejas plásticas planas com capacidade para 96 tubetes. Após a germinação, foram realizados raleios, deixando apenas a plântula de maior vigor em cada tubete. Os tubetes foram acondicionados em bandejas plásticas suspensas em estrutura metálica a 1 metro do solo. O tempo de formação das mudas foi de 4 meses.

Quando as plantas apresentaram $10 \mathrm{~cm} \pm 2 \mathrm{~cm}$ de altura, iniciaram-se os tratamentos de fertilização em cento e cinquenta mudas, que foram submetidas à adubação exponencial, tomando como referência o teor de $\mathrm{N}$ da semente até a concentração final de $100 \mathrm{mg} \mathrm{L}^{-1}$ de nitrogênio por muda. Para o cálculo da adubação exponencial, as sementes foram avaliadas em relação ao conteúdo de nitrogênio, utilizando a equação sugerida por Carrasco et al. (2001) cujo resultado foi adicionado à concentração de $100 \mathrm{mg} \mathrm{L}^{-1}$ e, posteriormente, aplicada em nove parcelas de 0,01; 0,$04 ; 0,12 ; 0,36 ; 1,02 ; 2,88 ; 8,13 ; 22,90$ e 64,4 mg de $N$ por muda.

Cento e cinquenta plantas de Eucalyptus grandis foram submetidas à adubação constante (100 mg L-1 de nitrogênio por planta) a cada 10 dias durante 3 meses (11,1 mg de $\mathbf{N}$ por muda), enquanto outras 150 plantas não receberam adubação com nitrogênio até o início do período de rustificação (controle).

A fertilização foi realizada manualmente utilizando como fonte de $\mathrm{N}$ a ureia (45\% de N) aplicada por meio de dispensador. Os demais nutrientes foram fornecidos igualmente para todos os tratamentos nas concentrações de 0,9 de $\mathrm{H}_{2} \mathrm{PO}_{4}^{-}$mmol L-1; 


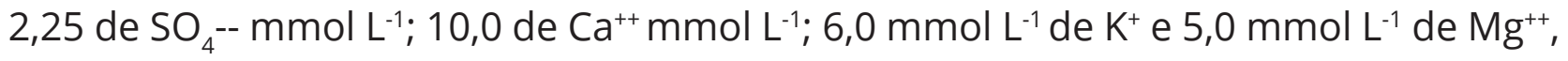
e 0,42 $\mathrm{mg} \mathrm{L}^{-1}$ de $\mathrm{Mn} ; 0,26 \mathrm{mg} \mathrm{L}^{-1}$ de $\mathrm{Zn} ; 0,05 \mathrm{mg} \mathrm{L}^{-1}$ de Cu; 0,50 $\mathrm{mg} \mathrm{L}^{-1}$ de $\mathrm{B} ; 0,04 \mathrm{mg} \mathrm{L}^{-1}$ de Mo e 4,82 $\mathrm{mg} \mathrm{L}^{-1}$ de quelato de Fe (FOGAÇA et al., 2007).

Quando as mudas apresentaram sinais de competição entre as folhagens, foi realizada a redução da ocupação nas bandejas plásticas pela metade, com a transferência para bandejas adicionais. As mudas foram irrigadas até a saturação do substrato, até três vezes ao dia quando a umidade relativa do ar estava abaixo de 30\% e a temperatura se encontrava acima de $30^{\circ} \mathrm{C}$.

As mudas foram alocadas aleatoriamente aos cinco tratamentos com seis repetições de cinco mudas, para os três regimes de fertilização. Cada tratamento consistiu da pulverização foliar de ácido 2-cloroetilfosfônico (Ethrel @, Rhône-Poulenc Agro Brasil, Portão, RS, BR com $240 \mathrm{~g} \mathrm{~L}^{-1}$ de ethephon, pH 6,0 substância inerte que libera etileno quando aplicada em solução aquosa) na formulação de $1.000 \mathrm{mg} \mathrm{L}^{-1}$, o qual foi estabelecido previamente, testando as doses de 0, 150, 300 e $600 \mathrm{mg} \mathrm{L}^{-1}$ (dados não apresentados) aplicados por 4 semanas.

As aplicações foram realizadas aditivamente conforme os seguintes tratamentos: T1 - sem aplicação de Ethephon (0), T2 - aplicação na primeira semana (1), T3 - aplicação na primeira e na segunda semanas (2), T4 - aplicação na primeira, segunda e terceira semanas (3), e T5 - aplicação na primeira, segunda, terceira e quarta semanas (4), para cada condição de adubação realizada, com rega diária por 30 dias em todas as mudas.

Ao final do período de imposição das aplicações de ethephon, as atividades das peroxidases foram determinadas em caules e raízes. O procedimento utilizou amostras de 0,2 g maceradas em almofariz com nitrogênio líquido, com $100 \mathrm{mmol}$ $\mathrm{L}^{-1}$ de solução de fosfato de sódio tamponada para $\mathrm{pH}$ 6,0 e mantida no gelo a uma proporção de $5 \mathrm{~mL}$ de tampão para cada grama de massa de folha fresca.

As amostras homogeneizadas foram centrifugadas a $11.600 \mathrm{rpm}$ por $15 \mathrm{~min}$ a $48^{\circ} \mathrm{C}$, e os sobrenadantes foram utilizados imediatamente como fonte de enzima. A atividade das peroxidases foi analisada seguindo a formação de tetraguaiacol com 
espectrofotômetro (Beckman®). A reação consistiu de 0,10 mL de extrato enzimático,2,9 $\mathrm{mL}$ de solução contendo $250 \mu \mathrm{L}$ de guaiacol e $306 \mu \mathrm{L}$ de peróxido de hidrogênio em $100 \mathrm{~mL}$ de tampão fosfato 0,01 M (pH 6,0). A atividade das peroxidases nos extratos foi quantificada através do aumento na leitura da absorbância a $470 \mathrm{~nm} \mathrm{~min}{ }^{-1} \mathrm{~g}$ de massa fresca-1 $^{-1}$ (LUSSO; PASCHOLATI, 1999).

A sobrevivência foi quantificada com o plantio das mudas em vasos de $18 \mathrm{~L}$ logo após a aplicação dos tratamentos. Os vasos foram preenchidos com solo argiloso (60\% de argila) e submetidos à irrigação até atingir a capacidade de campo. Cada tratamento foi representado por cinco vasos com duas mudas cada, dispostos sobre bancadas a 1,2 $\mathrm{m}$ do solo em ambiente protegido.

Após o plantio, as mudas foram submetidas à completa restrição hídrica por um período de 20 dias. Os dados de sobrevivência foram obtidos através da visualização semanal de todas as mudas até os 20 dias após a imposição da restrição hídrica. Mudas com todas as folhas secas e caule tortuoso foram consideradas mortas.

Para determinação das concentrações de nutrientes, a matéria seca obtida foi moída em moinho tipo Willey e passada em peneira de malha 40 mesh para a verificação das concentrações de nitrogênio $(N)$, fósforo $(P)$ e potássio $(K)$ nas folhas. Para avaliar as concentrações de N e P no tecido vegetal, utilizaram-se amostras de 0,2 g em quatro repetições por tratamento. As amostras foram submetidas à digestão sulfúrica e posterior destilação em aparelho semi-microKjeldhal, e espectrofotometria UV-VIS para determinação das concentrações de N e P, respectivamente, e K por fotometria de chama como descrito por Tedesco et al. (1995).

A concentração de lignina foi aferida a partir do método proposto por Peltier, Hatfield e Grau (2009) que consiste em separar 0,5 g de amostra para cada repetição. No presente ensaio, foram utilizadas amostras de matéria seca de caules de mudas de Eucalyptus grandis. Para cada amostra realizou-se extrações com $10 \mathrm{~mL}$ de solvente na seguinte ordem: três extrações com etanol (80\%), para remover açúcares e ácidos orgânicos; uma extração com acetona PA para remover flavonóides e pigmentos; uma 
extração em clorofórmio PA e metanol PA (2:1); e duas extrações com acetona PA. Após cada extração, o sobrenadante foi retirado e descartado, sendo que cada amostra foi agitada em Vortex e levada a banhos de ultrassons por 15 minutos em meio a cada extração. A centrifugação ocorreu a 5.000 rpm durante 10 min/extração. Após as extrações, as amostras foram secas em exaustor por 24 horas e levadas para estufa a $55^{\circ} \mathrm{C}$ até massa constante. Com o material completamente seco, transferiram-se 0,025 g de amostra para tubos de vidro de $10 \mathrm{~mL}(125 \times 16 \mathrm{~mm})$ com tampas de rosca; a esses tubos foram adicionados $2,5 \mathrm{~mL}$ de brometo de acetila e ácido acético glacial ( $25 \%$ de brometo de acetila e $75 \%$ de ácido acético glacial). Essa mistura foi levada ao banho-maria por 2 horas, agitando as amostras a cada 30 minutos. Após 2 horas, as amostras foram resfriadas em água em temperatura ambiente.

Retirou-se $1 \mathrm{~mL}$ da amostra obtida com o banho-maria a $40{ }^{\circ} \mathrm{C}$ e transferiu-se para tubos do tipo Eppendorf, seguido de centrifugação a 14.000 rpm por 1 min. Após a centrifugação, $0,5 \mathrm{~mL}$ do sobrenadante foi retirado e colocado em tubos de vidro de $20 \mathrm{~mL}$, onde se adicionou: 7,15 mL de ácido acético glacial, $2 \mathrm{~mL}$ de $\mathrm{NaOH}$ a $2 \mathrm{~mol} \mathrm{~L}^{-1}$, e $0,35 \mathrm{~mL}$ de hidroxilamina a $0,5 \mathrm{~mol} \mathrm{~L}^{-1}$. As amostras foram congeladas até a leitura espectrofotométrica. As leituras foram realizadas em espectrofotômetro (Shimadzu ${ }^{\circledR}$ modelo UVmini-1240) a $280 \mathrm{~nm}$. Após a leitura, os dados foram submetidos à equação de curva padrão sugerida por Fukushima e Kerley (2011):

$X=(y-0,0009) / 23,1$

onde: $X=$ concentração final de lignina $\left(\mathrm{mg} \mathrm{mL}^{-1}\right) ; y=$ densidade óptica obtida na leitura da amostra; 0,0009 = valor médio da intercepção; 23,1 = média do coeficiente de espectrograma obtida nas curvas padrão para espécies arbóreas no referido estudo.

Os dados foram submetidos aos testes de normalidade e homogeneidade (qui-quadrado e Bartlett). Quando constatada homogeneidade, os dados foram submetidos à análise de variância em esquema fatorial com testemunha adicional $(3 \times 4+1)$, formado por três tratamentos de fertilização e quatro aplicações de etileno mais uma testemunha sem aplicação, em seis blocos de cinco mudas por tratamento. Quando necessário, os dados foram submetidos ao teste de médias de Duncan a 5\% de probabilidade para comparação dos tratamentos, com o auxílio do aplicativo Genes. 


\section{RESULTADOS E DISCUSSÃO}

Os regimes de fertilização e as aplicações de ethephon durante a fase de rustificação em mudas de Eucalyptus grandis não resultaram em alterações significativas $(P>0,05)$ para as atividades das peroxidases no caule, e a sobrevivência de mudas sob restrição hídrica aos 20 dias após o plantio em vasos (DAP).

O aumento no número de aplicações de ethephon estimulou o aumento na concentração de lignina na parede celular do caule em mudas cultivadas submetidas aos regimes de fertilização testados, com os maiores valores verificados com a terceira aplicação do regulador vegetal (Tabela 1). Os menores valores para esse parâmetro foram obtidos em tecidos de mudas que receberam apenas a primeira aplicação do regulador vegetal e não fertilizadas com nitrogênio.

Tabela 1 - Concentração de lignina na parede celular das células do caule (PCC) e da raiz (PCR) em mudas de Eucalyptus grandis em função dos regimes de fertilização e das aplicações de ethephon

\begin{tabular}{|c|c|c|c|}
\hline \multirow{2}{*}{$\begin{array}{c}\mathbf{N}^{\circ} \text { de aplicações } \\
\text { de etileno }\end{array}$} & \multicolumn{3}{|c|}{ Regime de Fertilização } \\
\hline & Sem Nitrogênio & Exponencial & Convencional \\
\hline & \multicolumn{3}{|c|}{----- Lignina no caule (g Kg PCC) ------ } \\
\hline Testemunha & 207,42 Aab & $182,60 \mathrm{Bb}$ & $210,29 \mathrm{Aa}$ \\
\hline 1 & $188,46 \mathrm{Bd}$ & $190,87 \mathrm{Bb}$ & $205,57 \mathrm{Aa}$ \\
\hline 2 & $193,32 \mathrm{Acd}$ & $190,48 \mathrm{Ab}$ & $191,02 \mathrm{Ab}$ \\
\hline 3 & $210,74 \mathrm{Aa}$ & $205,50 \mathrm{Aa}$ & $209,16 \mathrm{Aa}$ \\
\hline \multirow[t]{2}{*}{4} & $199,98 \mathrm{Abc}$ & $203,25 \mathrm{Aa}$ & $206,71 \mathrm{Aa}$ \\
\hline & \multicolumn{3}{|c|}{------ Lignina na raiz (g Kg PCR) ------ } \\
\hline Testemunha & $193,59 \mathrm{Bb}$ & $205,26 \mathrm{Ab}$ & $198,49 \mathrm{ABb}$ \\
\hline 1 & $212,07 \mathrm{Aa}$ & $216,60 \mathrm{Aa}$ & $209,43 \mathrm{Aa}$ \\
\hline 2 & $206,43 \mathrm{Aa}$ & 210,13 Aab & $210,67 \mathrm{Aa}$ \\
\hline 3 & $190,07 \mathrm{Bb}$ & 206,58 Aab & 207,15 Aab \\
\hline 4 & $185,87 \mathrm{Bb}$ & 213,94 Aab & $176,89 \mathrm{BC}$ \\
\hline
\end{tabular}

Fonte: Schulz et al. (2014)

Em que: Médias seguidas pelas mesmas letras minúsculas na vertical e maiúscula na horizontal não diferem estatisticamente entre si pelo teste Duncan a 5\% de probabilidade de erro. 
As aplicações de ethephon estimularam o acúmulo de lignina na parede celular de raízes em mudas cultivadas sem nitrogênio, ou fertilizadas exponencial e convencionalmente (Tabela 1). Os maiores valores resultaram dos tratamentos que receberam o regulador vegetal (primeira e segunda aplicação de etileno) em relação à testemunha.

A maior concentração de lignina na parede celular em raízes de Eucalyptus grandis comprovou a sensibilidade da espécie até a segunda aplicação de etileno. A concentração de lignina nas mudas pode ser entendida como um indicador de rusticidade, pois teoricamente mudas mais rustificadas apresentam maiores concentrações de lignina em sua parede celular. A lignina é considerada uma macromolécula, com origem fenolpropanóide, de importância vital na planta suporte, proporcionando rigidez necessária para manter verticalidade do caule (MONTEIRO; PEREIRA; ABREU, 2004; MALAVASI; DAVIS; MALAVASI, 2016).

A sensibilidade da espécie ao regulador vegetal pode estar associada à atividade de enzimas pectinolíticas específicas, como a poligalacturonase e a endo$\beta-1,4-g l u c a n a s e$, que participam nos processos de degradação da parede celular. A atividade dessas enzimas associadas à ação do etileno pode ser influenciada por diversos fatores externos não controlados no presente ensaio, dentre eles, baixos teores de $\mathrm{O}_{2}$ ou altas temperaturas (JACOMINO et al., 2008). Portanto, há indícios de que as atividades enzimáticas acima mencionadas podem ter resultado na oxidação do etileno exógeno e resultar em menores valores das concentrações de ligninas nas maiores doses de ethephon aplicadas, apesar de não ter havido o controle de temperatura e $\mathrm{O}_{2}$ no presente experimento.

Abiossíntesedalignina éum processo complexoqueenvolveváriasrotas metabólicas. Segundo Marjamaa, Kukkola e Fagerstedt (2009), a partir da fenilananina secretada no citoplasma, ocorre a oxidação da parede celular pela ação das enzimas peroxidases, lacase ou fenol-oxidase. A fenilananina também é a uma das enzimas fenilpropanóides que leva a formação de precursores intermediários para a síntese da lignina. 
A atividade das peroxidases no caule e raiz (Tabela 2 ) em mudas de Eucalyptus grandis submetidas às aplicações de etileno e cultivadas em diferentes regimes de adubação não apresentaram interação significativa. Adicionalmente, a análise de variância individual não resultou em diferenças entre o tratamento testemunha e os tratamentos com ethephon, apresentando médias semelhantes.

Tabela 2 - Atividade das peroxidases na massa fresca do caule (MFC) e da raiz (MFR) em mudas de Eucalyptus grandis em função dos regimes de fertilização e das aplicações de ethephon

\begin{tabular}{|c|c|c|c|c|}
\hline \multirow{2}{*}{$\begin{array}{c}\mathbf{N}^{\circ} \text { de aplicações } \\
\text { de etileno }\end{array}$} & \multicolumn{3}{|c|}{ Regimes de Fertilização } & \multirow[b]{2}{*}{ Médias } \\
\hline & Sem Nitrogênio & Exponencial & Convencional & \\
\hline & \multicolumn{4}{|c|}{------ Absorbância (470 nm)/min/g MFC) ------- } \\
\hline Testemunha & 1,26 & 1,23 & 1,08 & $1,19 \mathrm{a}$ \\
\hline 1 & 1,38 & 1,45 & 1,20 & $1,31 \mathrm{a}$ \\
\hline 2 & 1,40 & 1,43 & 1,30 & $1,38 \mathrm{a}$ \\
\hline 3 & 1,47 & 1,65 & 1,30 & $1,47 a$ \\
\hline 4 & 1,53 & 1,65 & 1,44 & $1,54 a$ \\
\hline \multirow[t]{2}{*}{ Médias } & $1,41 \mathrm{~A}$ & $1,46 \mathrm{~A}$ & $1,26 \mathrm{~A}$ & \\
\hline & \multicolumn{4}{|c|}{------ Absorbância (470 nm)/min/g MFR) ------ } \\
\hline Testemunha & 0,92 & 0,99 & 0,96 & $0,96 \mathrm{a}$ \\
\hline 1 & 1,05 & 1,05 & 1,03 & $1,04 a$ \\
\hline 2 & 1,06 & 1,13 & 1,06 & $1,08 \mathrm{a}$ \\
\hline 3 & 0,93 & 1,39 & 1,02 & $1,11 \mathrm{a}$ \\
\hline 4 & 1,01 & 1,30 & 1,33 & $1,21 \mathrm{a}$ \\
\hline Médias & $0,99 \mathrm{~A}$ & $1,17 \mathrm{~A}$ & $1,08 \mathrm{~A}$ & \\
\hline
\end{tabular}

Fonte: Schulz et al. (2014)

Em que: Médias seguidas pelas mesmas letras maiúsculas na horizontal não diferem estatisticamente entre si pelo teste Duncan a 5\% de probabilidade de erro.

Os valores médios da atividade enzimática em raízes de Eucalyptus grandis submetidas às aplicações de ethephon não externaram alterações, diferentemente dos resultados obtidos por Donald e Cipollini (1998), que estudaram a atividade das peroxidases em resposta ao estímulo mecânico induzido e estímulo químico pela aplicação de cloreto de mercúrio $\left(5 \mathrm{mmol} \mathrm{L}^{-1} \mathrm{HgCl}_{2}\right.$ ). Os autores retro mencionados 
reportaram aumento da atividade das peroxidases em folhas de soja, tanto por meio do estímulo mecânico como do químico. No entanto, os mesmos autores destacaram que plantas expostas ao estímulo químico apresentaram necrose nas folhas, e que esse aumento da atividade das peroxidases pode ser devido à inibição da oxidação e cicatrização de feridas.

A concentração de nitrogênio em folhas de Eucalyptus grandis expostas às aplicações de ethephon resultou em diferenças $(P<0,05)$ quando comparadas as em mudas testemunha, bem como entre os demais tratamentos (Tabela 3).

Tabela 3 - Concentração de nitrogênio, fósforo e potássio em mudas de Eucalyptus grandis em função dos regimes de fertilização e das aplicações de ethephon

\begin{tabular}{|c|c|c|c|}
\hline \multirow{2}{*}{$\begin{array}{c}\mathbf{N}^{\circ} \text { de aplicações de } \\
\text { etileno }\end{array}$} & \multicolumn{3}{|c|}{ Regimes de Fertilização } \\
\hline & Sem Nitrogênio & Exponencial & Convencional \\
\hline & \multicolumn{3}{|c|}{------ Nitrogênio $\left(\mathrm{mg} \mathrm{g}^{-1}\right)$------ } \\
\hline Testemunha & 0,72 Bab & $1,57 \mathrm{Abc}$ & 1,62 Aa \\
\hline 1 & $0,68 \mathrm{Ca}$ & 1,54 Aab & $1,15 \mathrm{Bb}$ \\
\hline 2 & $0,68 \mathrm{Cb}$ & 1,79 Aa & $1,06 \mathrm{Bb}$ \\
\hline 3 & $0,72 \mathrm{Cab}$ & $1,49 \mathrm{Ac}$ & $1,10 \mathrm{Bb}$ \\
\hline 4 & $0,88 \mathrm{Ca}$ & 1,72 Aab & 1,49 Ba \\
\hline \multirow[t]{2}{*}{ Médias } & - & - & - \\
\hline & \multicolumn{3}{|c|}{------ Fósforo $\left(\mathrm{mg} \mathrm{g}^{-1}\right)$------- } \\
\hline Testemunha & $0,92 \mathrm{Cd}$ & $1,59 \mathrm{Bb}$ & 2,09 Aa \\
\hline 1 & $1,10 \mathrm{Cc}$ & $1,31 \mathrm{Bd}$ & 2,05 Aa \\
\hline 2 & $1,07 \mathrm{Cc}$ & $1,51 \mathrm{BC}$ & $1,95 \mathrm{Ab}$ \\
\hline 3 & $1,32 \mathrm{Bb}$ & $1,56 \mathrm{Abc}$ & $1,59 \mathrm{AC}$ \\
\hline 4 & $1,44 \mathrm{Ca}$ & $1,67 \mathrm{Aa}$ & $1,54 \mathrm{BC}$ \\
\hline \multirow[t]{2}{*}{ Médias } & - & - & - \\
\hline & \multicolumn{3}{|c|}{------ Potássio $\left(\mathrm{mg} \mathrm{g}^{-1}\right)$------ } \\
\hline Testemunha & 16400,00 Aa & $12400,00 \mathrm{Bb}$ & $12930,00 \mathrm{Ba}$ \\
\hline 1 & 15840,00 Aa & 14150,00 Ba & $11710,00 \mathrm{Cb}$ \\
\hline 2 & $14620,00 \mathrm{Ab}$ & $13900,00 \mathrm{Ab}$ & $11400,00 \mathrm{Bb}$ \\
\hline 3 & $14030,00 \mathrm{Ab}$ & $12370,00 \mathrm{Bb}$ & 6370,000 Cc \\
\hline 4 & $13560,00 \mathrm{Ab}$ & $14000,00 \mathrm{Aa}$ & $6620,000 \mathrm{Bc}$ \\
\hline Médias & - & - & - \\
\hline
\end{tabular}

Fonte: Schulz et al. (2014)

Em que: Médias seguidas pelas mesmas letras minúsculas na vertical e maiúscula na horizontal não diferem estatisticamente entre si pelo teste Duncan a 5\% de probabilidade de erro. 
Houve interação entre os tratamentos avaliados, sendo a maior média obtida na fertilização exponencial com duas aplicações de ethephon. Os menores valores foram quantificados em mudas que não receberam fertilização nitrogenada com duas aplicações de ethephon, comportamento semelhante àquele aferido com a concentração de lignina no caule, apesar de não haver correlação para as médias gerais destes parâmetros (Tabela 4).

Tabela 4 - Coeficientes de correlação de Pearson entre variáveis fisiológicas em mudas de Eucalyptus grandis

\begin{tabular}{|c|c|c|c|c|c|c|c|c|c|}
\hline & \multicolumn{9}{|c|}{ Variáveis } \\
\hline & S10 & $S 20$ & LC & LigR & PC & PR & $\mathbf{N}$ & $\mathbf{P}$ & $K$ \\
\hline $\mathrm{S} 10$ & & 0.28 & 0.10 & -0.07 & $-0.26 *$ & -0.14 & -0.19 & -0.00 & 0.04 \\
\hline S20 & & & -0.14 & 0.25 & -0.22 & -0.23 & -0.02 & .03 & 0.18 \\
\hline LigC & & & & $-0.32 *$ & 0.15 & 0.06 & -0.06 & 0.16 & $-0.24^{*}$ \\
\hline LigR & & & & & -0.01 & -0.02 & 0.21 & 0.10 & $0.23 *$ \\
\hline PC & & & & & & $0.31 *$ & $0.29 *$ & 0.09 & -0.17 \\
\hline PR & & & & & & & 0.02 & -0.18 & 0.02 \\
\hline N & & & & & & & & $0.47 *$ & -0.21 \\
\hline$P$ & & & & & & & & & -0.45 * \\
\hline K & & & & & & & & & \\
\hline
\end{tabular}

Fonte: Schulz et al. (2014)

Em que: S10 = sobrevivência 10 dias após o plantio; S20 = sobrevivência 20 dias após o plantio; LigC = Lignina caule; LigR = Lignina raiz; $\mathrm{PC}=$ atividade da enzima peroxidase no caule; $\mathrm{PR}=$ atividade da enzima peroxidase na raiz; $\mathrm{N}=$ Nitrogênio; $\mathrm{P}=$ Fósforo; $\mathrm{K}=$ Potássio. ${ }^{*}$ ) significativo a $5 \%$ de probabilidade pelo teste $t$.

Esse comportamento sugere que tanto a concentração de lignina quanto a concentração de nitrogênio nas plantas expressaram menores valores a partir de duas aplicações de ethephon, resultando em efeito autoinibitório. Godoy et al. (1997) destacaram que pode ocorrer relação negativa entre o crescimento, teor de nitrogênio, teor de lignina e os compostos fenólicos em plantas, característica versada pelas interrelações e consequente concorrência das vias bioquímicas no metabolismo vegetal. Esta concorrência ocorre por competição dos precursores fenilpropanóides entre a 
síntese de taninos e a de ligninas, dois grupos expressivos de metabólitos fenólicos secundários. Por outro lado, o metabolismo fenólico é mantido em equilíbrio com o metabolismo do nitrogênio.

Trabalhando com aplicação de ácido jasmônico em Eucalyptus urophylla, Monteiro (2005) destacou a correlação entre o crescimento das mudas e o teor de lignina, mas não necessariamente afirmou que o aumento no teor de lignina equivale a uma maior altura das mudas.

Pela análise de correlação de Pearson, a sobrevivência de mudas aferida aos 10 DAP resultou em correlação negativa somente para a atividade da enzima peroxidase, indicativa de que quanto menores os valores para atividade das peroxidases, maiores as porcentagens de sobrevivência das mudas. Resultados semelhantes para atividade das enzimas peroxidases em mudas de feijoeiro (Phaseolus vulgaris L.), submetidas ao estresse hídrico foram descritos por Souza et al. (2015). Embora não refletindo na porcentagem de sobrevivência, as atividades das enzimas polifenoloxidase e ascorbato peroxidase reduziram com a exposição ao estresse hídrico de 50\% da capacidade de campo ao solo.

Uma das condições adversas encontradas por mudas recém plantadas a campo é o déficit hídrico, sendo uma das respostas dos vegetais às alterações bioquímicas em nível celular, como, por exemplo, as atividades das peroxidases, possivelmente para manutenção do potencial hídrico da folha (SOUZA et al., 2015). Adicionalmente, Campos et al. (2004) constataram que as enzimas oxidativas como catalase, polifenoloxidase e ascorbato peroxidase apresentam atividade alterada com o aumento do estresse abiótico.

O potássio tem sido adicionado a substratos a fim de aumentar a eficiência das mudas na utilização da umidade do solo, afirmação que pode ser comprovada pela correlação positiva entre a concentração de potássio e a concentração de lignina na raiz. Kafkafi (1990) afirmou que, sob deficiência hídrica, as plantas acumulam potássio como uma estratégia de segurança para permitir sua sobrevivência a uma deficiência hídrica repentina. 
A análise de correlação indicou ainda que a concentração de lignina no caule apresentou correlação negativa com a concentração de lignina na raiz, assim como a concentração de lignina no caule não se correlaciona com a concentração de potássio e de fósforo.

Contrastante ao explicitado no parágrafo acima, correlações significativas positivas resultaram entre as variáveis peroxidase no caule e na raiz, bem como peroxidase no caule e concentração de N, e entre concentração de N e P (Tabela 4). Esse contraste indicou que o crescimento celular aéreo, bem como a peroxidação e a lignificação do tecido é inversamente proporcional ao da raiz, caracterizando uma estratégia de defesa da planta aos estresses bióticos e abióticos, como a aplicação de ethephon e níveis de fertilização. Segundo Gonçalves (2013), uma alteração metabólica importante para as plantas em condições de estresse é o aumento da produção de enzimas reativas de oxigênio, como as peroxidases. Esses ajustes no metabolismo celular das plantas também provocam acúmulo de açúcares e proteínas, que podem explicar o aumento na concentração de $\mathrm{N}$ na raiz.

As mudas cultivadas em regime convencional de fertilização apresentaram menores valores para a concentração de fósforo em comparação à testemunha, em função da aplicação de ethephon (Tabela 3). Já as mudas cultivadas sem nitrogênio e com fertilização de forma exponencial responderam de maneira contrária, com a máxima concentração de fósforo acumulada quantificada em mudas que receberam quatro aplicações de ethephon. Segundo Smith e Read (1997), o ethrel utilizado como fonte do ethephon causa a liberação de fosfato. O argumento explica o aumento na concentração de fósforo para os regimes zero $\mathrm{N}$ (controle) e o exponencial. Já a fertilização convencional apresentou valores iniciais altos de fósforo, e a aplicação do ethephon causou fitotoxidez e inibição da liberação de fosfatos.

As respostas para as aplicações de ethephon em mudas de Eucalyptus grandis limitaram a absorção de potássio quando fertilizadas convencionalmente e exponencialmente, bem como o aumento do número de aplicações de ethephon 
resultou em menores valores de potássio nas folhas (Tabela 4). Os maiores valores foram quantificados em mudas fertilizadas com zero $\mathrm{N}$ em até uma aplicação do regulador vegetal.

Na literatura, as informações são rarefeitas acerca dos efeitos de aplicações de reguladores vegetais na absorção de nutrientes. No entanto, alguns estudos indicaram que o aumento nas taxas ou utilização de regimes exponenciais de fertilização melhoraram consideravelmente o nível de nutrientes de mudas de Quercus ilex L. (VILLAR-SALVADOR et al., 2004; OLIET et al., 2009) conforme resultados quantificados em relação à absorção de nitrogênio (Tabela 4).

Nesse sentido, constata-se que a forma do cultivo em viveiro pode influenciar significativamente a fisiologia das mudas de Eucalyptus grandis e, consequentemente, o desempenho pós-plantio. A fase inicial de crescimento, na qual a muda permanece no viveiro é importante para obtenção de mudas de boa qualidade, que complementada com a rustificação garantem o sucesso e a sobrevivência a campo. Os resultados obtidos no presente experimento enfatizam a potencialidade da aplicação de reguladores vegetais como indutores da rustificação em mudas de Eucalyptus grandis.

A sobrevivência aos 10 e aos 20 DAP das mudas transplantadas para vasos e mantidas sob restrição hídrica não resultaram em interação, bem como a testemunha não configurou em diferenças em relação aos tratamentos com aplicações de ethephon (Tabela 5).

Dranski (2013) destacou a impossibilidade em avaliar o efeito de qualidade das mudas sobre o estabelecimento de plantações como uma variável isolada. A qualidade das mudas relaciona-se à ecologia e ao clima existentes em cada área de plantio, bem como à variação em função do tempo e do espaço, requerendo mudas com diferentes níveis de qualidade e especificidades. Adicionalmente, Davis e Jacobs (2005) reportaram que a qualidade de mudas está relacionada com sua composição genética, com o vigor - ou seja, as condições apropriadas de crescimento em viveiro -, e principalmente com as condições ambientais do local de plantio. 
Em mudas de Eucalyptus grandis os regimes de fertilização exponencial e convencional promoveram aumento da concentração de lignina e do nitrogênio quando comparados com o regime sem nitrogênio, resultando em valores maiores, principalmente com até duas aplicações de ethephon na fase de rustificação, sendo um indicador de aumento na qualidade de mudas da espécie. Porém, a análise dos resultados indicou ausência para as variáveis atividade das peroxidases em caules e raízes e sobrevivência das mudas.

Tabela 5 - Sobrevivência aos 10 e 20 dias após o plantio (DAP) em vasos de mudas de Eucalyptus grandis em função de regimes de fertilização e das aplicações de ethephon

\begin{tabular}{lcccc}
\hline \multirow{2}{*}{$\begin{array}{c}\text { N. de aplicações } \\
\text { de etileno }\end{array}$} & \multicolumn{4}{c}{ Regimes de Fertilização } \\
\cline { 2 - 5 } & Sem Nitrogênio & Exponencial & Convencional & Médias \\
\hline Testemunha & 80 & 60 & 100 & $80 \mathrm{a}$ \\
1 & 70 & 80 & 80 & $76 \mathrm{a}$ \\
2 & 100 & 80 & 100 & $93 \mathrm{a}$ \\
3 & 100 & 70 & 60 & $76 \mathrm{a}$ \\
4 & 70 & 20 & 90 & $60 \mathrm{a}$ \\
Médias & $84 \mathrm{~A}$ & $62 \mathrm{~A}$ & $86 \mathrm{~A}$ & \\
\hline & & 40 & 40 & $40 \mathrm{a}$ \\
\hline Testemunha & 40 & 50 & 40 & $43 \mathrm{a}$ \\
1 & 40 & 30 & 40 & $36 \mathrm{a}$ \\
2 & 40 & 30 & 30 & $30 \mathrm{a}$ \\
3 & 30 & 10 & 20 & $20 \mathrm{a}$ \\
4 & 30 & $34 \mathrm{~A}$ & $34 \mathrm{~A}$ & \\
\hline
\end{tabular}

Fonte: Schulz et al. (2014)

Em que: Médias seguidas pelas mesmas letras minúsculas na vertical e maiúscula na horizontal não diferem estatisticamente entre si pelo teste Duncan a 5\% de probabilidade de erro.

\section{CONCLUSÃO}

Os regimes de fertilização, exponencial e convencional, bem como as pulverizações semanais de etileno induziram alterações fisiológicas na fase de 
rustificação em mudas de Eucalyptus grandis com duas aplicações de ethephon. As alterações consistiram principalmente na redução da concentração de fósforo e potássio, bem como no acúmulo de lignina na parede celular em raízes de mudas cultivadas sem nitrogênio, com nitrogênio exponencial e convencional, porém sem efeito sobre a sobrevivência.

\section{AGRADECIMENTOS}

À Capes, à Universidad de Alcalá e ao CNPq.

\section{REFERÊNCIAS}

CAMPOS, A. D. et al. Atividade de peroxidase e polifenoloxidase na resistência do feijão à antracnose. Pesquisa Agropecuária Brasileira, Brasília, v. 39, p. 637-643, 2004.

CASAL, J. J. et al. Phytochrome-mediated effects on extracellular peroxidase activity, lignin content and bending resistance in etiolated Viciafaba epicotyls. Physiologia Plantarum, [s. I.], v. 92, p. 555-562, 1994.

CARRASCO, I. et al. Fertilización convencional y exponencial con diferentes dosis em plantas de Pinus halepensis y Pinus nigra cultivadas en contendor. In: CONGRESO FORESTAL ESPAÑOL, 3., 2001, Granada. Actas[...]. Granada: [s. n.], 2001. v. 3. p. 757-762.

DAVIS, A. S.; JACOBS, D. F. Quantifying root system quality of nursery seedlings and relationship to out planting performance. New Forests, [s. I.], v. 30, n. 2/3, p. 295-311, 2005.

DRANSKI, J. A. L. et al. Effect of ethephon on hardening of Pachystroma longifolium seedlings. Revista Árvore, Viçosa, MG, v. 37, n. 3, p. 401-407, 2013.

DONALD F.; CIPOLLINI, J. R. The induction of soluble peroxidase activity in bean leaves by wind-induced mechanical perturbation. American Journal of Botany, Lancaster, v. 85, n. 11, p. 1586-1591, 1998.

ERNER, Y.; JAFFE, M. J. Thigmomorphogenesis, the involvement of auxin and abscisic acid in growth retardation due to mechanical perturbation. Plant Cell Physiology, [s. I.], v. 23, n. 6, p. 935-941, 1982.

FOGAÇA, M. A. F. et al. Concentração de nitrogênio na solução nutritiva, na produtividade e na qualidade de frutos de melão cultivado em substrato. Ciência Rural, Santa Maria, v. 37, n. 1, 2007. 
FUKUSHIMA, R. S.; KERLEY, M. S. Use of lignin Extracted from different plant sources as standards in the spectrophotometric acetyl bromide lignin method. Journal of Agriculture and Food Chemistry, [s. I.], v. 59, p. 3505-3509, 2011.

GODOY, S. A. P. de et al. Teores de ligninas, nitrogênio e taninos em folhas de espécies típicas do mangue. Revista Brasileira de Botânica, São Paulo, v. 20, n. 1, 1997.

GONÇALVES, K. S. Aplicação de reguladores vegetais e de fosfito de potássio em mudas de eucalipto submetidas à deficiência hídrica. 2013. Tese (Doutorado) - Faculdade de Ciências Agronômicas da UNESP, Botucatu, 2013.

INDÚSTRIA BRASILEIRA DE ÁRVORES. Anuário estatístico IBÁ 2018 ano base 2017. Brasília, 2018.

JACOMINO, A. P. et al. Transformações bioquímicas em hortícolas após a colheita. In: KOBLITZ, M. G. B. Bioquímica de alimentos: teoria e aplicações práticas. Rio de Janeiro, Guanabara Koogan, 2008. cap. 6.

KAFKAFI, $U$. The functions of plant $\mathrm{K}$ in overcoming environmental stress situations. COLLOQUIUM OFTHE INTERNATIONAL POTASH INSTITUTE, 22., 1990, Soligorsk. In: Proceedings [...]. Soligorsk: International Potash Institute, 1990. 385 p.

LOPES, J. L. W. et al. Crescimento inicial do eucalipto em função da aclimatação em viveiro. Irriga, Botucatu, v. 16, n. 2, p. 199-211, 2011.

LUSSO, M. F. G.; PASCHOLATI, S. F. Activity and isoenzymatic pattern of soluble peroxidases in maize tissues after mechanical injury or fungal inoculation. Summa Phytopathologica, Botucatu, v. 25, p. 244-249, 1999.

MALAVASI, U. C.; DAVIS, A. S.; MALAVASI, M. M. Lignin in woody plants under water stress: a review. Floresta e Ambiente, Seropédica, v. 23, n. 4, p. 589-597, 2016.

MARJAMAA, K.; KUKKOLA, E. M.; FAGERSTEDT, K. V. The role of xylem class III peroxidases in lignification. Journal of Experimental Botany, [s. I.], v. 60, n. 2, p. 367-376, 2009.

MONTEIRO, M. B. O. Modulação do processo de lignificação por aplicação de ácido jasmônico e ácido 2,4-Diclorofenoxiacético em Eucalyptus urophylla. 2005. Dissertação (Mestrado) - Universidade Federal Rural do Rio de Janeiro, Instituto de Florestas, Seropédica, 2005.

MONTEIRO, M. B. O.; PEREIRA, R. P. W.; ABREU, H. S. Bioquímica da lignificação de células xilemáticas. Floresta e Ambiente, Seropédica, v. 11, n. 2, p. 48-57, 2004.

OLIET, J. et al. Field performance of Pinus halepensis planted in Mediterranean arid conditions: relative influence of seedling morphology and mineral nutrition. New Forest, [s. I.], v. 37, p. 313-33, 2009.

ORO, P. et al. Aplicação de regulador vegetal na aclimatação de mudas de Cariniana estrellensis. Cultivando Saber, Cascavel, v. 5, n. 4, p. 103-112, 2012. 
PELTIER, A. J.; HATFIELD, R. D.; GRAU, C. R. Soy bean stem lignin concentration relates to resistance to Sclerotinia sclerotiorum. Plant Disease, Saint Paul, v. 93, p. 149-154, 2009.

SMITH, S. E.; READ, D. J. Mycorrhizal Symbiosis. 2th ed. London: Academic Press, 1997. 605 p.

SOUZA, C. A. M. et al. Crescimento em campo de espécies florestais em diferentes condições de adubação. Ciência Florestal, Santa Maria, v. 16, n. 3, p. 243-249, 2006.

SOUZA, C. C. M. et al. Crescimento e respostas enzimáticas do feijoeiro caupi sob estresse hídrico e nematoide de galhas. Revista Brasileira de Engenharia Agrícola e Ambiental, Campina Grande, v. 19, n. 2, p.113-118, 2015.

TEDESCO, M. J. et al. Análises de solo, plantas e outros materiais. Porto Alegre: Universidade Federal do Rio Grande do Sul, Faculdade de Agronomia, 1995. 174 p.

VILLAR-SALVADOR, P. et al. Drought tolerance and transplanting performance of holm oak (Quercus ilex) seedlings after drought hardening in the nursery. Tree Physiology, Victoria, v. 24, p. 1147-1155, 2004.

YAMADA, T.; CASTRO, P. R. C. Efeitos do glifosato nas plantas: implicações fisiológicas e agronômicas. Encarte do Informações Agronômicas, [s. I.], n. 119, 2007.

\section{Contribuição de Autoria}

\section{1 - Deisinara Giane Schulz}

Bióloga, Dra., Professora

https://orcid.org/0000-0001-6414-0510•deisinarags@gmail.com

Contribuição: Investigação, Conceituação, Análise Formal, Supervisão, Metodologia, Investigação, Visualisação, Curadoria de dados, Escrita - primeira redação

\section{2 - Michelle Cristina Ajala}

Bióloga, Dra.

https://orcid.org/0000-0003-4803-0842•michelleajala@hotmail.com

Contribuição: Metodologia, Investigação, Curadoria de dados

\section{3 - Marlene de Matos Malavasi}

Engenheira Agrônoma, Dra., Professora

https://orcid.org/0000-0002-6726-6490•marlenemalavasi@gmail.com

Contribuição: Escrita - revisão e edição, Administração do projeto, Supervisão 


\section{4 - Ubirajara Contro Malavasi}

Engenheiro Florestal, Dr., Professor

https://orcid.org/0000-0003-4300-4338•biramalavasi@gmail.com

Contribuição: Escrita- revisão e edição, Conceituação, Supervisão, Validação, Obtenção de financiamento, Administração do projeto, Recursos

\section{Como citar este artigo}

Schulz, D. G.; Ajala, M. C.; Malavasi, M. M.; Malavasi, U. C. Alterações fisiológicas em mudas de Eucalyptus grandis (Hill) ex Maiden submetidas à fertilização nitrogenada e ação do etileno. Ciência Florestal, Santa Maria, v. 31, n. 1, p. 85-105, 2021. DOI 10.5902/1980509822318. Disponível em: https://doi.org/10.5902/1980509822318. Acesso em: xx mês abreviado 202x. 